\title{
Heart rate variability and target organ damage in hypertensive patients
}

Paolo Melillo ${ }^{1 *}$, Raffaele Izzo ${ }^{2}$, Nicola De Luca² and Leandro Pecchia ${ }^{3}$

\begin{abstract}
Background: We evaluated the association between linear standard Heart Rate Variability (HRV) measures and vascular, renal and cardiac target organ damage (TOD).

Methods: A retrospective analysis was performed including 200 patients registered in the Regione Campania network (aged $62.4 \pm 12$, male 64\%). HRV analysis was performed by 24-h holter ECG. Renal damage was assessed by estimated glomerular filtration rate (eGFR), vascular damage by carotid intima-media thickness (IMT), and cardiac damage by left ventricular mass index.

Results: Significantly lower values of the ratio of low to high frequency power (LF/HF) were found in the patients with moderate or severe eGFR ( $p$-value $<0.001$ ). Similarly, depressed values of indexes of the overall autonomic modulation on heart were found in patients with plaque compared to those with a normal IMT ( $p$-value <0.05). These associations remained significant after adjustment for other factors known to contribute to the development of target organ damage, such as age. Moreover, depressed LF/HF was found also in patients with left ventricular hypertrophy but this association was not significant after adjustment for other factors.
\end{abstract}

Conclusions: Depressed HRV appeared to be associated with vascular and renal TOD, suggesting the involvement of autonomic imbalance in the TOD. However, as the mechanisms by which abnormal autonomic balance may lead to TOD, and, particularly, to renal organ damage are not clearly known, further prospective studies with longitudinal design are needed to determine the association between HRV and the development of TOD.

Keywords: Heart Rate Variability, Target organ damage, Hypertension

\section{Background}

Cardiovascular (CV) diseases are one of the most leading causes of morbidity and mortality in high developed countries [1]. A number of prospective population or cohort studies, such as the Atherosclerosis Risk in Communities Study [2], the Rotterdam Study [3], the Cardiovascular Health Study [4], and the Carotid Atherosclerosis Progression Study [5], have shown that asymptomatic organ damage is significantly related to incident $\mathrm{CV}$ events. If $\mathrm{CV}$ involvement is early detected by physicians, it is possible to influence the progression or regression of the disease by the therapy [6]. Although there is still a little information on the specific causes of these pathologies, a recent review by Thayer suggested that autonomic imbalance may be a final common pathway to

\footnotetext{
* Correspondence: paolo.melillo@unina2.it

${ }^{1}$ Multidisciplinary Department of Medical Sciences, Second University of Naples, Via Pansini, 5, Naples, Italy

Full list of author information is available at the end of the article
}

increased morbidity and mortality from a host of conditions and pathologies, including CV diseases [7]. Analysis of heart rate variability (HRV) on the basis of routine 24-hour Holter recordings has been shown to provide a sensitive measurement of cardiac control by the autonomous nervous system (ANS) [8,9]. HRV is a non-invasive measure reflecting the variation over time of the period between consecutive heartbeats (RR intervals) [8]. In fact, heart rate (HR), which continuously fluctuates over time, is under the influence of control mechanisms aimed at maintaining a dynamic stability called homoeostasis [10]. In this equilibrium, the sympathetic stimulation causes acceleration in HR by increasing the firing rate of pacemaker cells in the heart's sino-atrial node, while the parasympathetic system causes deceleration in HR by decreasing of the firing rate of pacemaker cells [8]. Clinical studies have shown reduced HRV in patients with congestive heart failure [11-16], diabetes [17], and white 
coat hypertension [18]. Moreover, decreased HRV measures have been shown to be a risk factor for mortality in chronic haemodialysis patients [19] and for progression to end-stage renal disease [20,21]. Furthermore, several studies have shown that incidence of $\mathrm{CV}$ events can be reduced by therapeutic correction of any modifiable risk factors, such as hypertension, abnormal cholesterol, diabetes, smoking habit or physical inactivity. As noted and shown in the review by Thayer [7], there is at least some data to suggest that each of these risk factors is associated with decreased HRV. Regarding hypertensive patients a sympatho-vagal imbalance as evaluated by HRV with increased sympathetic activity and reduced vagal tone has been reported [22] and a recent paper by Garcia-Garcia [23] investigate the correlation between heart rate and the parameters that assess vascular, renal and cardiac target organ damage (TOD). However, only two HRV measures were selected in the study by GarciaGarcia [23]. The aim of the current study was to evaluate the association between linear standard HRV measures with the vascular, renal and cardiac TOD in hypertensive patients registered in the Campania Salute network. The Campania Salute network is an open registry collecting information from a network of general practitioners and community hospitals networked with the centre, and providing a centralised database including demographics and clinical information of the patients.

\section{Methods}

\section{Population study}

For the present study, among the initial cohort of 12,000 patients registered in the database of the Campania Salute Network, we selected all the hypertensive subjects who underwent at least one visit in the Outpatient Hypertension Clinic of the University of Naples "Federico II" from 2000 to 2010 and were evaluated by a cardiac and carotid ultrasonography and by a $24 \mathrm{~h}$ Holter ECG. The ECG Holter was performed after a one-month antihypertensive therapy wash-out. Details on this cohort have been previously reported [24,25]. Exclusion criteria for the present analysis were: diagnosis of secondary resistant and/or uncontrolled hypertension, prevalent CV disease, clinical history of cancer, liver cirrhosis and/or failure, narcotics abuse, lifestyle changes in the last 12 months. Moreover, patients with atrial fibrillation and frequent ectopic beats as assessed by Holter were excluded. Prevalent CV disease was defined as history of previous myocardial infarction or angina or procedures of coronary revascularization, stroke or transitory ischemic attack, congestive heart failure, chronic kidney disease more than grade $3\left(\mathrm{eGFR}\right.$ by MDRD $<30 \mathrm{~mL} / \mathrm{min} / 1.73 \mathrm{~m}^{2}$ ) at the time of the first examination in the outpatient clinic. Prevalent CV disease was excluded by an ad-hoc committee in the Hypertension Centre, based on patients' history, contact with the referring general practitioner and clinical records documenting the occurrence of disease. In the sub-cohort of 10254 patients with arterial hypertension, 4257 patients were excluded for diagnosis of secondary resistant and/or uncontrolled hypertension, prevalent $\mathrm{CV}$ disease, clinical history of cancer, liver cirrhosis and/or failure, narcotics abuse, lifestyle changes in the last 12 months; 1814 for chronic kidney disease more than grade 3 (eGFR by $\mathrm{MDRD}<30 \mathrm{~mL} / \mathrm{min} / 1.73 \mathrm{~m}^{2}$ ); 2556 for missing data (i.e. ultrasonography, holter ECG); 942 for atrial fibrillation and 485 for frequent ectopic beats.

\section{Ethical issues}

All the data of the patients (i.e. medical history, physical examination, routine laboratory tests and other diagnostic procedures) were stored in the computerised database of Campania Salute Network. The database generation of the Campania Salute Network was approved by the Federico II University Hospital Ethic Committee. All the participants signed informed consent to use data for scientific purposes.

\section{Protocol}

At the first visit all patients were given a detailed questionnaire inquiring about specifics lifestyle behaviours and smoking habit. In the current study they were categorised as non-smokers, ex-smokers or smokers. During the visits, blood pressure (BP), lipid and glucose profiles were measured for each patient by standard methods. Diagnosis and stratification of essential hypertension was performed according to the criteria established by the Guidelines for the Management of Arterial Hypertension [26]: systolic and diastolic BP were measured by a standard aneroid sphygmomanometer after $5 \mathrm{~min}$ rest in the supine position, according to the current guidelines [26]. Three BP measurements were obtained at 2-min intervals. The averages of these measurements were used for the analysis. Glomerular filtration rate (eGFR) was estimated by the Modification of Diet in Renal Disease (MDRD) formula [27]. Diabetes was defined as a fasting blood glucose $\geq 126 \mathrm{mg} / \mathrm{dL}$ or active glucose-lowering therapy [28].

\section{Echocardiography}

Two-dimensional-guided M-mode echocardiograms were performed using a dedicated ultrasound machine (SONOS 5500, Philips) with an ultrasound transducer of $2.5 \mathrm{MHz}$. The examinations were recorded on a digital recorder and analysed by three independent, trained and experienced physicians. The parameters relative to the left ventricle (LV) were measured in the parasternal long-axis view and obtained, according to the criteria of the American Society 
of Echocardiography [29], as an average of at least three measurements, as also performed in previous studies [30,31]. LV mass was determined by using the formula developed by Devereux [32] as recommend by American Society of Echocardiography (ASE) [33] and divided by the body surface area to calculate LV mass index (LVMi, $\mathrm{g} / \mathrm{m}^{2}$ ). Intraoperator and interassay variability were $5 \%$ and $6 \%$, respectively [34].

\section{Carotid ultrasound}

B-mode ultrasonography of carotid arteries was performed with patients in the supine position with the neck extended in mild rotation. The scanning protocol was performed with an ultrasound device (SONOS 5500, Philips) equipped with a 7.5-MHz high-resolution transducer with an axial resolution of $0.1 \mathrm{~nm}$. Examinations were recorded on S-VHS videotapes. All measurement were analysed by three different trained experienced physicians. An average of two readings was considered for subsequent calculations. The accuracy of determinations was evaluated as previously described by Lembo et al. [35]: the variability of measurements to evaluate intrasonographer and intersonographer reproducibility was 0.01 and $0.03 \mathrm{~mm}$, respectively. The maximum arterial intima media thickness (IMT) in up to 12 arterial walls, including the right and the left, near and far distal common carotid $(1 \mathrm{~cm})$, bifurcation, and proximal internal carotid artery was estimated offline with an image processing workstation with the software COMPACS (Rev. 10.5.8, Medimatic, Genoa, Italy).

\section{Assessment of TOD}

Cardiac Involvement was evaluated as Left Ventricular Hypertrophy (LVH) which was diagnosed if LVMi exceeded $110 \mathrm{~g} / \mathrm{m}^{2}$ in female and $125 \mathrm{~g} / \mathrm{m}^{2}$ in male [36]. Vascular involvement was assessed as carotid artery atherosclerosis shown by increased IMT in B-mode ultrasonography. IMT values between 1.0 and $1.3 \mathrm{~mm}$ were defined as "thickening" and those higher than $1.3 \mathrm{~mm}$ as "plaque". Chronic kidney disease was assessed by eGFR and involvement was quantified as follows:

1. group 1: increased or normal eGFR (eGFR $\geq$ $90 \mathrm{~mL} / \mathrm{min} / 1.73 \mathrm{~m}^{2}$ )

2. group 2: mild eGFR $(60<\mathrm{eGFR}<90 \mathrm{~mL} / \mathrm{min} /$ $1.73 \mathrm{~m}^{2}$ )

3. group 3: moderate eGFR (eGFR $\leq 60 \mathrm{~mL} / \mathrm{min} /$ $\left.1.73 \mathrm{~m}^{2}\right)[37]$

\section{Processing 24-hour holter recordings}

On 2 consecutive days, patients underwent a 24-hour ECG Holter recording. The recorders were applied between 9 and $11 \mathrm{AM}$ on a working day, and the patients were asked to follow as closely as possible their usual daily activities during each monitoring session. They were asked to stay in bed from $11 \mathrm{PM}$ to $7 \mathrm{AM}$, and all reported to have slept normally during the nights they were monitored. The series of normal to normal (NN) beat intervals were obtained from ECG recordings using OSAS, an open-source software for QRS detection and beat classification [38]. Standard long-term HRV analysis on nominal 24-h recordings according to International Guidelines was performed [8]. The HRV analysis was performed using PhysioNet's HRV Toolkit [39]. We chose this toolkit as it is an open source and a rigorously validated package. All the computed basic time- and frequency-domain HRV measures were widely used in the literature [8]. A number of standard statistical time-domain HRV measures are calculated: Average of all NN intervals (AVNN), standard deviation of all $\mathrm{NN}$ intervals (SDNN), standard deviation of the averages of $\mathrm{NN}$ intervals in all 5-min segments of a 24-h recording (SDANN), mean of the standard deviations of NN intervals in all 5-min segments of a 24-h recording (SDNN IDX), square root of the mean of the sum of the

Table 1 Characteristics of the study sample of patients

\begin{tabular}{ll}
\hline Characteristic & Value \\
\hline Age (years) & $62.5 \pm 12.1$ \\
\hline Sex (male/female, \%) & $63.5 / 36.5$ \\
\hline Family history of hypertension (yes/no, \%) & $56.5 / 43.5$ \\
\hline Family history of stroke (yes/no, \%) & $19.5 / 80.5$ \\
\hline Smokers (yes/ex/no, \%) & $17.5 / 21 / 61.5$ \\
\hline Diabetes (yes/no, \%) & $10 / 90$ \\
\hline Diastolic BP (mmHg) & $75.6 \pm 12.0$ \\
\hline Systolic BP (mmHg) & $133.2 \pm 22.6$ \\
\hline Pulse pressure (mmHg) & $57.6 \pm 17.8$ \\
\hline Fasting blood glucose (mmHg) & $102.7 \pm 24.1$ \\
\hline Total Cholesterol (mg/dl) & $185.8 \pm 40.6$ \\
\hline BMl (kg/m²) & $27.7 \pm 4.6$ \\
\hline Beta-blockers (yes/no, \%) & $33.5 / 66.5$ \\
\hline Alphabeta-blockers (yes/no, \%) & $10.5 / 89.5$ \\
\hline Alpha-blockers (yes/no, \%) & $8 / 92$ \\
\hline Diuretics (yes/no, \%) & $43.5 / 56.5$ \\
\hline ACE inhibitor (yes/no, \%) & $37.5 / 62.5$ \\
\hline Dihydropyridine (yes/no, \%) & $26 / 74$ \\
\hline eGFR (mL/min/1.73 m²) & $77.0 \pm 18.9$ \\
\hline Kidney Involvement (group 1/ 2 /3 \%) & $24 / 59.5 / 16.5$ \\
\hline IMT (mm) & $2.24 \pm 1.56$ \\
\hline Vascular abnormalities (no/ thickening/plaque, \%) & $13 / 11 / 78$ \\
\hline LVMi g/m² & $130.5 \pm 31.0$ \\
\hline Left Ventricular hypertrophy (no/yes, \%) & $40 / 60$ \\
\hline Data are exprssed as mean and sand & \\
\hline
\end{tabular}

Data are expressed as mean and standard deviation for continuous variables (i.e. age) and as percentage of patients per each group for categorical variables (i.e. gender). 
squares of differences between adjacent $\mathrm{NN}$ intervals (RMSSD), percentage of differences between adjacent NN intervals that are longer than $50 \mathrm{~ms}$ (pNN50). The frequency-domain HRV measures rely on the estimation of power spectral density (PSD) computed, in this work, by Lomb-Scamble periodogram [40]. After PSD estimation, six standard frequency-domain HRV measures were calculated: total spectral power of all NN intervals up to $0.4 \mathrm{~Hz}$ (TOTPWR), between 0 and $0.003 \mathrm{~Hz}$ (ULF), between 0.003 and $0.04 \mathrm{~Hz}$ (VLF), between 0.04 and $0.15 \mathrm{~Hz}$ (LF), and between 0.15 and $0.4 \mathrm{~Hz}(\mathrm{HF})$, ratio of low to high frequency power (LF/HF).

\section{Statistical analysis}

Data were analysed by the use of PASW Statistics 18 software (Release 18.0; SPSS IBM, Chicago, IL, USA). Univariate differences were analysed using Kruskal-Wallis and Wilcoxon test for HRV measures, ANOVA and ttest for the other continuous variables (for instance age, IMT, etc.) and $\chi^{2}$ test for the categorical variables (for instance sex, smoking). For each HRV measure, which differs significantly among the three groups, an adjusted model was proposed by performing a binary or multinomial logistic regression, as appropriate. For each factor or covariate, the coefficient of the estimated regression model $(\beta)$, the corresponding statistical significance $(p)$, the odds ratio (OR) and the confidence interval for OR at $95 \%$ are presented. A p-value less than $5 \%$ was considered statistically significant.

\section{Results}

200 patients were analysed (127 male and 73 female). Demographic, clinical and laboratory characteristics of the study sample are shown in Table 1 . Table 2 shows the characteristic of the study sample of patients categorised by eGFR. The moderate eGFR group is significantly older than the others and has a significantly higher proportion of patients taking diuretics. Systolic BP and Pulse Pressure values were significantly higher in mild decreased eGFR group (compared to normal eGFR group), where

Table 2 Characteristics of the study sample of patients stratified according to the eGFR

\begin{tabular}{|c|c|c|c|c|c|c|c|}
\hline & \multirow{2}{*}{$\begin{array}{l}\text { Normal } \\
\text { eGFR } \\
\text { (group 1) }\end{array}$} & \multirow{2}{*}{$\begin{array}{c}\text { Mild } \\
\text { decreased } \\
\text { eGFR } \\
\text { (group 2) }\end{array}$} & \multirow{2}{*}{$\begin{array}{l}\text { Moderate } \\
\text { decreased } \\
\text { eGFR } \\
\text { (group 3) }\end{array}$} & \multicolumn{4}{|c|}{ P Values } \\
\hline & & & & $\begin{array}{c}\text { ANOVA or } \\
\mathrm{X}^{2}\end{array}$ & $\begin{array}{c}\text { group } 1 \text { vs } \\
\text { group } 2\end{array}$ & $\begin{array}{l}\text { group } 1 \text { vs } \\
\text { group } 3\end{array}$ & $\begin{array}{c}\text { group } 2 \text { vs } \\
\text { group } 3\end{array}$ \\
\hline Age (years) & $56 \pm 11.5$ & $63,0 \pm 11.7$ & $70.0 \pm 9.4$ & $<0.001$ & 0.001 & $<0.001$ & 0.05 \\
\hline Gender (male/female) & $31 / 17$ & $76 / 43$ & $20 / 13$ & 0.928 & & & \\
\hline Family history of hypertension (yes/no) & $25 / 23$ & $69 / 50$ & $19 / 14$ & 0.778 & & & \\
\hline Family history of stroke (yes/no) & $11 / 37$ & 22/97 & $6 / 27$ & 0.790 & & & \\
\hline Smokers (yes/ex/no) & $13 / 8 / 27$ & $8 / 27 / 7$ & $27 / 75 / 21$ & 0.379 & & & \\
\hline Diabetes (yes/no) & $5 / 43$ & $11 / 108$ & $4 / 29$ & 0.883 & & & \\
\hline Diastolic BP (mmHg) & $73.2 \pm 14.0$ & $77.3 \pm 11.5$ & $73.0 \pm 9.8$ & 0.048 & 0.129 & 1 & 0.185 \\
\hline Systolic BP (mmHg) & $124.5 \pm 23.3$ & $137.5 \pm 20.0$ & $130.2 \pm 27.3$ & 0.002 & 0.002 & 0.754 & 0.286 \\
\hline Pulse pressure $(\mathrm{mmHg})$ & $51.3 \pm 14.1$ & $60.1 \pm 16.9$ & $57.3 \pm 23.3$ & 0.014 & 0.010 & 0.396 & 1 \\
\hline Fasting blood glucose $(\mathrm{mmHg})$ & $99.7 \pm 32.2$ & $102.8 \pm 20.0$ & $106.7 \pm 23.9$ & 0.432 & 1 & 0.589 & 1 \\
\hline Total Cholesterol (mg/dl) & $178.9 \pm 36.4$ & $187.7 \pm 40.8$ & $189.0 \pm 45.8$ & 0.395 & 0.610 & 0.817 & 1 \\
\hline $\mathrm{BMI}\left(\mathrm{kg} / \mathrm{m}^{2}\right)$ & $27.4 \pm 5.2$ & $28.1 \pm 4.6$ & $26.7 \pm 3.5$ & 0.261 & 1 & 1 & 0.379 \\
\hline Beta-blockers (yes/no) & $15 / 33$ & $41 / 78$ & $11 / 22$ & 0.924 & & & \\
\hline Alphabeta-blockers (yes/no) & $5 / 43$ & $14 / 105$ & $2 / 31$ & 0.639 & & & \\
\hline Alpha-blockers (yes/no) & $3 / 45$ & $8 / 111$ & $5 / 28$ & 0.252 & & & \\
\hline Diuretics (yes/no) & $17 / 31$ & $49 / 70$ & $21 / 12$ & 0.03 & & & \\
\hline ACE inhibitor (yes/no) & $16 / 32$ & $48 / 71$ & $11 / 22$ & 0.604 & & & \\
\hline Dihydropyridine (yes/no) & $12 / 36$ & $30 / 89$ & $10 / 23$ & 0.826 & & & \\
\hline eGFR (mL/min/1.73 m²) & $101.9 \pm 12.0$ & $74.3 \pm 8.8$ & $50.6 \pm 8.0$ & $<0.001$ & $<0.001$ & $<0.001$ & $<0.001$ \\
\hline $\mathrm{IMT}(\mathrm{mm})$ & $1.8 \pm 0.76$ & $2.23 \pm 1.21$ & $2.91 \pm 2.85$ & 0.007 & 0.282 & 0.005 & 0.81 \\
\hline Vascular abnormalities (no/ thickening/plaque) & $33 / 6 / 9$ & $91 / 13 / 15$ & $28 / 3 / 2$ & 0.502 & & & \\
\hline LVMi g/m² & $124.3 \pm 26.2$ & $133.0 \pm 32.3$ & $130.4 \pm 32.1$ & 0.258 & 0.301 & 1 & 1 \\
\hline Left Ventricular hypertrophy (no/yes) & $24 / 24$ & $44 / 75$ & $12 / 21$ & 0.268 & & & \\
\hline
\end{tabular}

Data are expressed as mean and standard deviation for continuous variables (i.e. age) and as number of patients per each group for categorical variables

The $\mathrm{p}$-values refer to ANOVA and post-hoc comparisons with Bonferroni corrections for continuous variables, to $x^{2}$ for categorical variables. 
Table 3 Comparisons of HRV measurement in patients stratified by eGFR

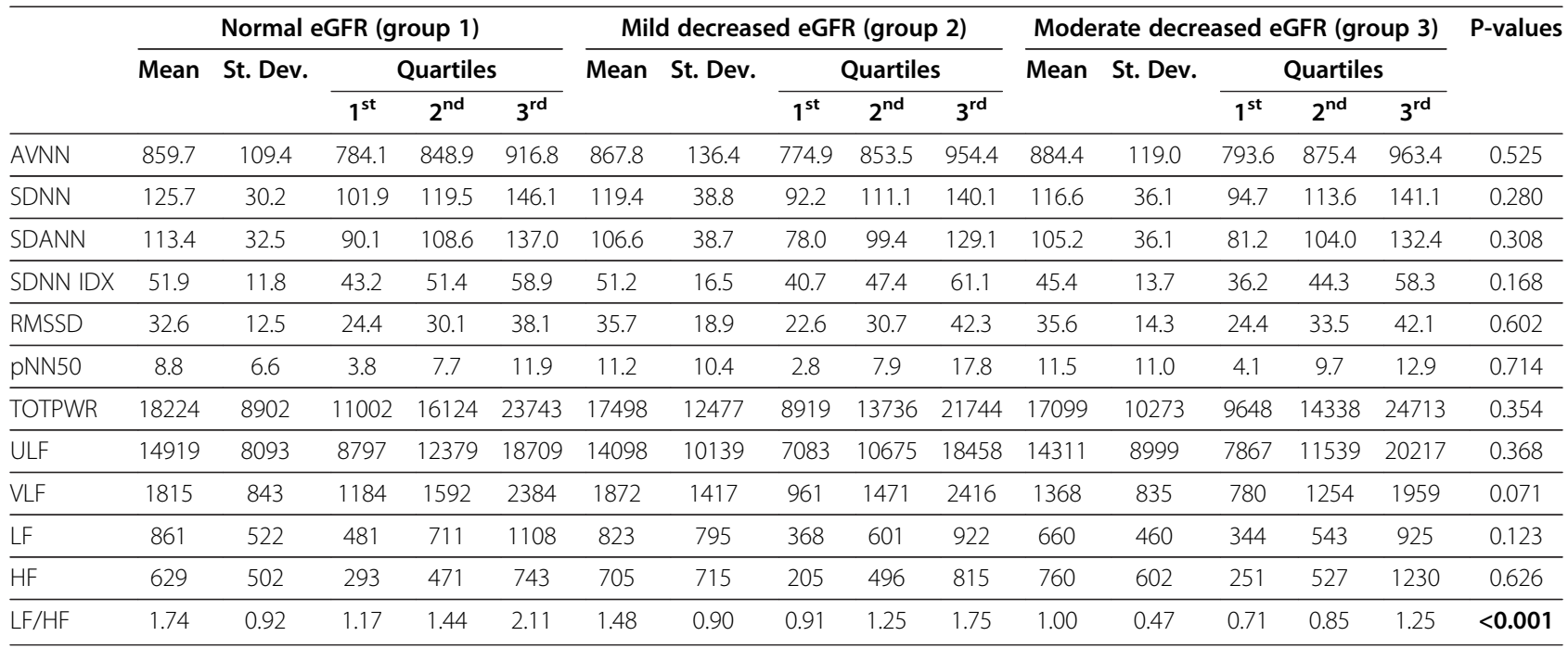

St. Dev. standard deviation.

The $p$-values refer to Kruskal-Wallis test.

Table 4 Characteristics of the study sample of patients stratified according to IMT

\begin{tabular}{|c|c|c|c|c|c|c|c|}
\hline & \multirow[t]{2}{*}{ Normal } & \multirow[t]{2}{*}{ Thickening } & \multirow[t]{2}{*}{ Plaque } & \multicolumn{4}{|c|}{ P Values } \\
\hline & & & & $\begin{array}{c}\text { ANOVA or } \\
x^{2}\end{array}$ & $\begin{array}{l}\text { Normal vs } \\
\text { Thickening }\end{array}$ & $\begin{array}{l}\text { Normal vs } \\
\text { Plaque }\end{array}$ & $\begin{array}{l}\text { Thickening vs } \\
\text { Plaque }\end{array}$ \\
\hline Age (years) & $47.3 \pm 13.3$ & $57.0 \pm 9.6$ & $65.9 \pm 9.8$ & $<0.001$ & 0.004 & $<0.001$ & 0.001 \\
\hline Sex (male/female) & $16 / 10$ & $10 / 12$ & $101 / 51$ & 0.157 & & & \\
\hline Family history of hypertension (yes/no) & $16 / 10$ & $18 / 4$ & $79 / 73$ & 0.026 & & & \\
\hline Family history of stroke (yes/no) & $4 / 22$ & $6 / 16$ & $29 / 123$ & 0.564 & & & \\
\hline Smokers (yes/ex/no) & $4 / 3 / 19$ & $6 / 2 / 14$ & $25 / 37 / 90$ & 0.242 & & & \\
\hline Diabetes (yes/no) & $2 / 24$ & $1 / 21$ & $17 / 135$ & 0.572 & & & \\
\hline Diastolic BP (mmHg) & $76.5 \pm 10.8$ & $73.4 \pm 18.6$ & $75.8 \pm 11.1$ & 0.643 & 1 & 1 & 1 \\
\hline Systolic BP (mmHg) & $131.5 \pm 19.2$ & $124.1 \pm 33.2$ & $134.8 \pm 21.1$ & 0.106 & 0.768 & 1 & 0.113 \\
\hline Pulse pressure $(\mathrm{mmHg})$ & $55.0 \pm 14.9$ & $50.6 \pm 19.9$ & $59.0 \pm 17.8$ & 0.086 & 1 & 0.856 & 0.117 \\
\hline Fasting blood glucose $(\mathrm{mmHg})$ & $98.0 \pm 20.7$ & $95.7 \pm 22.0$ & $104.5 \pm 24.7$ & 0.154 & 1 & 0.601 & 0.321 \\
\hline Total Cholesterol (mg/dl) & $182.0 \pm 38.0$ & $192.0 \pm 39.1$ & $185.6 \pm 41.4$ & 0.687 & 1 & 1 & 1 \\
\hline $\mathrm{BMI}\left(\mathrm{kg} / \mathrm{m}^{2}\right)$ & $28.8 \pm 5.4$ & $27.3 \pm 3.7$ & $27.6 \pm 4.6$ & 0.395 & 0.747 & 0.596 & 1 \\
\hline Beta-blockers (yes/no) & $15 / 11$ & $6 / 16$ & $46 / 106$ & 0.019 & & & \\
\hline Alphabeta-blockers (yes/no) & $1 / 25$ & $3 / 19$ & $17 / 135$ & 0.465 & & & \\
\hline Alpha-blockers (yes/no) & $1 / 25$ & $2 / 20$ & $13 / 139$ & 0.702 & & & \\
\hline Diuretics (yes/no) & $9 / 17$ & $8 / 14$ & $70 / 82$ & 0.429 & & & \\
\hline ACE inhibitor (yes/no) & $10 / 16$ & $8 / 14$ & $57 / 95$ & 0.989 & & & \\
\hline Dihydropyridine (yes/no) & $7 / 19$ & $4 / 18$ & $41 / 111$ & 0.675 & & & \\
\hline eGFR $\left(\mathrm{mL} / \mathrm{min} / 1.73 \mathrm{~m}^{2}\right)$ & $84.1 \pm 17.5$ & $81.2 \pm 17.8$ & $75.2 \pm 19.1$ & 0.045 & 1 & 0.077 & 0.479 \\
\hline Renal involvement & $9 / 15 / 2$ & $6 / 13 / 3$ & $33 / 91 / 28$ & 0.502 & & & \\
\hline $\mathrm{IMT}(\mathrm{mm})$ & $0.89 \pm 0.11$ & $1.19 \pm 0.08$ & $2.62 \pm 1.61$ & $<0.001$ & 1 & $<0.001$ & $<0.001$ \\
\hline LVMi $\mathrm{g} / \mathrm{m}^{2}$ & $109.6 \pm 19.0$ & $126.7 \pm 33.2$ & $134.6 \pm 30.9$ & $<0.001$ & 0.149 & $<0.001$ & 0.744 \\
\hline Left Ventricular hypertrophy (no/yes) & $20 / 6$ & $11 / 11$ & $49 / 103$ & $<0.001$ & & & \\
\hline
\end{tabular}

Data are expressed as mean and standard deviation for continuous variables (i.e. age) and as number of patients per each group for categorical variable (i.e. gender). The $p$-value refers to ANOVA and post-hoc comparison with Bonferroni corrections for continuous variables and to $x^{2}$ for categorical variables. 
IMT values were significantly lower in normal eGFR group (compared to moderate decreased eGFR group). Table 3 shows the descriptive statistics of HRV measures in the groups stratified by eGFR. The three groups differed significantly in LF/HF. Table 4 shows the characteristic of the study sample of patients categorised by IMT. The Plaque group is significantly older than the others. LVMi values were significantly lower in the normal group compared to the Plaque group and the proportion of patients with LVH was significantly lower. A significantly higher proportion of patients with family history of hypertension was assessed in the Thickening group. A significant difference in the proportion of patients taking beta-blockers was observed. Table 5 shows the descriptive statistics of HRV measures in the three groups according to IMT. The three groups differed significantly in SDNN, SDANN, SDNN IDX TOTPWR, LF, and LF/ HF. Table 6 shows the characteristic of the study sample of patients categorised by LVH. The LVH group is significantly older than the group without LVH. IMT values were significantly higher in the LVH group and the proportion of patients with vascular abnormalities was significantly higher. A significantly higher proportion of patients taking diuretics was assessed in LVH group. The values of Systolic BP and Pulse Pressure were significantly higher in the LVH group. Table 7 shows the comparison of HRV measures in the patients with and without LVH. The two groups differed significantly in LF/HF. Most differences persisted even in the adjusted models, which are reported in Table 8. As concerns renal TOD, the multinomial logistic regression selected age, family history of hypertension and systolic BP. Higher values of $\mathrm{LF} / \mathrm{HF}$ are associated with an increased probability that a subject belongs to normal or mild eGFR groups rather than to moderate group (OR 2.718 and 2.637, respectively). Older age is associated with a decreased probability of being in normal or mild decreased eGFR groups (OR 0.897 and 0.943, respectively). The absence of family history of hypertension is associated with an increased probability of belonging to normal eGFR group (OR 2.951). Elevated systolic BP seems to be associated with a slightly increased probability of belonging to mild decreased eGFR group (OR 1.024). As regards vascular TOD, the adjusted models confirmed the differences in the values of SDNN and SDANN. In fact, higher values of SDNN and SDANN are associated with an increased probability that a subject had no vascular alterations rather than plaque. Moreover, this model confirms that older age is associated with vascular alterations. As regards cardiac TOD, the binomial logistic regression did not confirm the difference in LF/ $\mathrm{HF}$ and showed that other variables are associated with LVH such as age, systolic BP, cholesterol, and diuretics.

\section{Discussion}

To our knowledge, the current study is the first one to investigate standard linear HRV measures, both in time and in frequency domains, in hypertensive patients, categorised by severity of TOD at different levels (cardiac, vascular and renal) and considering adjusted models for age and other clinical parameters (such as gender, metabolic variables). Time and power spectral analysis of 24-hour electrocardiographic monitoring was performed in 200 hypertensive patients in basal conditions. At these same times, patients underwent echocardiographic and carotid ultrasonography study evaluations

Table 5 Comparisons of HRV measurement in the group of patients stratified by IMT

\begin{tabular}{|c|c|c|c|c|c|c|c|c|c|c|c|c|c|c|c|c|}
\hline & \multicolumn{5}{|c|}{ Normal IMT } & \multicolumn{5}{|c|}{ Thickening } & \multicolumn{5}{|c|}{ Plaque } & \multirow[t]{3}{*}{ P-value } \\
\hline & \multirow[t]{2}{*}{ Mean } & \multirow[t]{2}{*}{ St. Dev. } & \multicolumn{3}{|c|}{ Quartiles } & \multirow[t]{2}{*}{ Mean } & \multirow[t]{2}{*}{ St. Dev. } & \multicolumn{3}{|c|}{ Quartiles } & \multirow[t]{2}{*}{ Mean } & \multirow[t]{2}{*}{ St. Dev. } & \multicolumn{3}{|c|}{ Quartiles } & \\
\hline & & & $1^{\text {st }}$ & $2^{\text {nd }}$ & $3^{\text {rd }}$ & & & $1^{\text {st }}$ & $2^{\text {nd }}$ & $3^{\text {rd }}$ & & & $1^{\text {st }}$ & $2^{\text {nd }}$ & $3^{\text {rd }}$ & \\
\hline AVNN & 830.0 & 123.5 & 749.2 & 821.6 & 916.2 & 842.3 & 141.8 & 746.7 & 820.5 & 957.3 & 879.0 & 124.7 & 797.1 & 864.8 & 952.0 & 0.116 \\
\hline SDNN & 140.1 & 48.8 & 105.3 & 132.3 & 171.3 & 121.7 & 34.3 & 94.2 & 115.3 & 147.2 & 116.9 & 33.3 & 93.3 & 111.6 & 136.9 & 0.049 \\
\hline SDANN & 128.4 & 49.7 & 88.2 & 124.8 & 157.9 & 110.8 & 34.7 & 81.0 & 102.2 & 138.3 & 104.1 & 33.5 & 80.3 & 98.5 & 124.1 & 0.046 \\
\hline SDNN IDX & 58.9 & 19.0 & 44.4 & 55.2 & 73.1 & 50.7 & 13.8 & 43.0 & 48.9 & 56.5 & 49.0 & 14.2 & 38.8 & 47.4 & 59.5 & 0.042 \\
\hline RMSSD & 36.9 & 13.5 & 26.8 & 32.2 & 42.6 & 30.7 & 11.7 & 22.1 & 29.7 & 34.0 & 35.2 & 17.9 & 22.7 & 30.5 & 41.7 & 0.216 \\
\hline pNN50 & 12.5 & 9.1 & 5.9 & 8.2 & 16.5 & 9.2 & 9.1 & 2.8 & 6.1 & 11.3 & 10.6 & 10.0 & 3.1 & 8.3 & 15.5 & 0.195 \\
\hline TOTPWR & 24209 & 16727 & 12113 & 19664 & 31647 & 17583 & 10891 & 9798 & 14497 & 22534 & 16480 & 9863 & 9300 & 13860 & 21255 & 0.049 \\
\hline ULF & 19550 & 13805 & 9436 & 16075 & 25947 & 14453 & 9137 & 7958 & 11822 & 18562 & 13420 & 8327 & 7216 & 10942 & 17851 & 0.092 \\
\hline VLF & 2590 & 1944 & 1113 & 2117 & 3172 & 1746 & 1101 & 1091 & 1514 & 1862 & 1640 & 1027 & 960 & 1325 & 2251 & 0.052 \\
\hline $\mathrm{LF}$ & 1255 & 1040 & 471 & 1006 & 1863 & 819 & 627 & 493 & 688 & 934 & 726 & 595 & 357 & 568 & 934 & 0.009 \\
\hline $\mathrm{HF}$ & 813 & 685 & 305 & 542 & 1299 & 566 & 517 & 178 & 499 & 617 & 694 & 661 & 229 & 477 & 914 & 0.376 \\
\hline LF/HF & 1.78 & 0.98 & 1.05 & 1.53 & 2.25 & 2.02 & 1.25 & 1.14 & 1.55 & 2.71 & 1.33 & 0.75 & 0.82 & 1.13 & 1.68 & 0.002 \\
\hline
\end{tabular}

St. Dev. standard deviation.

The $p$-values refer to Kruskal-Wallis test. 
Table 6 Characteristics of the study sample of patients with and without LVH

\begin{tabular}{|c|c|c|c|}
\hline & \multicolumn{2}{|c|}{ LVH } & \multirow[t]{2}{*}{$P$ values } \\
\hline & $\begin{array}{l}\text { Patient Group } \\
\text { with LVH }\end{array}$ & $\begin{array}{l}\text { Patient group } \\
\text { without LVH }\end{array}$ & \\
\hline Age (years) & $56.8 \pm 12.1$ & $66.3 \pm 10.6$ & 0.001 \\
\hline Sex (male/female) & $49 / 31$ & $78 / 42$ & 0.589 \\
\hline $\begin{array}{l}\text { Family history of } \\
\text { hypertension (yes/no) }\end{array}$ & $48 / 32$ & $65 / 55$ & 0.415 \\
\hline $\begin{array}{l}\text { Family history of stroke } \\
\text { (yes/no) }\end{array}$ & $15 / 65$ & $24 / 96$ & 0.827 \\
\hline Smokers (yes/ex/no) & $17 / 18 / 45$ & $18 / 24 / 78$ & 0.404 \\
\hline Diabetes (yes/no) & $2 / 78$ & $18 / 102$ & 0.004 \\
\hline Diastolic BP (mmHg) & $73.8 \pm 12.1$ & $76.8 \pm 11.8$ & 0.094 \\
\hline Systolic BP (mmHg) & $126.1 \pm 25.3$ & $137.9 \pm 19.4$ & 0.001 \\
\hline Pulse pressure $(\mathrm{mmHg})$ & $52.3 \pm 18.0$ & $61.1 \pm 16.8$ & 0.001 \\
\hline $\begin{array}{l}\text { Fasting blood glucose } \\
(\mathrm{mmHg})\end{array}$ & $99.8 \pm 23.6$ & $104.7 \pm 24.3$ & 0.161 \\
\hline Total Cholesterol (mg/dl) & $191.0 \pm 38.6$ & $182.3 \pm 41.7$ & 0.132 \\
\hline BMI $\left(\mathrm{kg} / \mathrm{m}^{2}\right)$ & $27.2 \pm 4.3$ & $28.0 \pm 4.8$ & 0.235 \\
\hline Beta-blockers (yes/no) & $31 / 49$ & $36 / 84$ & 0.199 \\
\hline $\begin{array}{l}\text { Alphabeta-blockers } \\
\text { (yes/no) }\end{array}$ & $7 / 73$ & $14 / 106$ & 0.510 \\
\hline Alpha-blockers (yes/no) & $5 / 75$ & $11 / 109$ & 0.456 \\
\hline Diuretics (yes/no) & $25 / 55$ & $62 / 58$ & 0.004 \\
\hline ACE inhibitor (yes/no) & $25 / 55$ & $50 / 70$ & 0.136 \\
\hline Dihydropyridine (yes/no) & $17 / 63$ & $35 / 85$ & 0.211 \\
\hline eGFR (mL/min/1.73 $\left.\mathrm{m}^{2}\right)$ & $79.9 \pm 17.9$ & $75.1 \pm 19.5$ & 0.071 \\
\hline Kidney Involvement (1/2 /3) & $24 / 44 / 12$ & $24 / 75 / 21$ & 0.268 \\
\hline IMT (mm) & $1.82 \pm 0.93$ & $2.52 \pm 1.82$ & $<0.001$ \\
\hline $\begin{array}{l}\text { Vascular abnormalities } \\
\text { (no/ thickening/plaque) }\end{array}$ & $20 / 11 / 49$ & $6 / 11 / 103$ & $<0.001$ \\
\hline LVMi $\mathrm{g} / \mathrm{m}^{2}$ & $105.0 \pm 13.8$ & $147.5 \pm 27.3$ & $<0.001$ \\
\hline
\end{tabular}

Data are expressed as mean and standard deviation for continuous variables (i.e. age) and as number of patients per each group for categorical variable (i.e. gender).

The $\mathrm{p}$-values refer to $\mathrm{t}$-test for continuous variables and $\mathrm{x}^{2}$ for categorical variables.

and routine laboratory evaluations in order to assess TOD at different level. The data of the current study showed that significantly lower values of some HRV measures were found in patients with $\mathrm{CV}$ involvement at different levels. Particularly, decreased LF/HF, which is a marker of sympatho-vagal balance, was found in the patients with moderate decreased eGFR, the highest grade of kidney involvement considered in this study. Similarly, depressed values of indexes of the overall ANS modulation on the heart, such SDNN and SDANN, were found in patients with plaque compared to patients with a normal IMT. These associations remained significant after adjustment for other factors known to contribute to the development of TOD, including diabetes, hypertension, and metabolic variables. Moreover, depressed LF/HF was found also in patients with LVH but this association was not significant after adjustment for other factors. As stated in a recent paper by Garcia-Garcia [23] the association between HRV and the development of TOD or vascular alterations has not been clearly established. Garcia-Garcia [23] investigated the association between 24-hours heart rate and IMT, LVMi, and eGFR, by performing a cross-sectional study including 360 hypertensive patients without heart rate lowering drugs, aged 30-80 years. We underline that they computed only two HR parameters: the mean HR and the standard deviation of HR (which are similar to AVNN and SDNN computed in the current study, respectively), while in this study almost all the linear HRV measures were computed as recommended and standardised in International Guidelines [8] and confirmed by recent literature [9]. Moreover, we proposed a larger number of covariates than Garcia-Garcia [23] in the adjusted model, for instance, the familiarity for hypertension or stroke. They found no association between AVNN and SDNN with LVH, consistently with our results. Moreover, they found associations between AVNN and SDNN with respect to IMT and eGFR, but these were lost after adjusting for age. Our results were coherent with these findings, even if in our studies the association of SDNN with IMT was significant also after adjustment. However, the patients in the study by Garcia-Garcia [23] were younger ( $56 \pm 11$ years versus $62 \pm 12$ years) and with a lower percentage of heart (18\% vs $60 \%$ ), and vascular (23\% vs $75 \%$ ) TOD. Moreover, the HRV analysis in this study was performed after a one-month antihypertensive therapy wash-out while many patients in the sample studied by Garcia-Garcia received drug therapy (not HR lowering drugs). We underline that the therapy before ECG holter measurement among selected groups was comparable as no significant differences occurred. The only exception was represented by diuretics, as a larger proportion of patients in the moderate eGFR group assumed diuretics compared with the other two groups (mild and normal eGFR) and a larger proportion of patients in the hypertrophy group assumed them compared to the group without hypertrophy. This difference was due to the fact that the antihypertensive treatment of patients with moderate decreased eGFR or with hypertrophy was based on the combination of diuretics with other drugs (i.e. Beta-blockers, ACE inhibitor, AT1 Antagonist and Dihydropyridine) which were usually prescribed also in the other groups of patients. We underline that the association of diuretics with a lower HRV has been already shown by the ARIC study [41] in 3577 hypertensive patients and by a recent study [42] in general male population, for that reason we performed the HRV analysis after a drug washout. The comparison of our results 
Table 7 Comparisons of HRV measurement in the group of patients with and without LVH

\begin{tabular}{|c|c|c|c|c|c|c|c|c|c|c|c|}
\hline & \multicolumn{5}{|c|}{ Patients with LVH } & \multicolumn{5}{|c|}{ Patients without LVH } & \multirow[t]{3}{*}{$P$ values } \\
\hline & \multirow[t]{2}{*}{ Mean } & \multirow[t]{2}{*}{ St. Dev. } & \multicolumn{3}{|c|}{ Quartiles } & \multirow[t]{2}{*}{ Mean } & \multirow[t]{2}{*}{ St. Dev. } & \multicolumn{3}{|c|}{ Quartiles } & \\
\hline & & & $1^{\text {st }}$ & $2^{\text {nd }}$ & $3^{\text {rd }}$ & & & $1^{\text {st }}$ & $2^{\text {nd }}$ & $3^{\text {rd }}$ & \\
\hline AVNN & 846.9 & 121.8 & 772.6 & 829.5 & 916.8 & 883.1 & 129.2 & 789.9 & 863.7 & 963.8 & 0.071 \\
\hline SDNN & 123.5 & 37.0 & 101.5 & 118.3 & 142.3 & 118.4 & 36.0 & 91.8 & 112.7 & 142.4 & 0.247 \\
\hline SDANN & 111.2 & 37.6 & 88.0 & 106.7 & 128.7 & 105.9 & 36.3 & 79.4 & 99.0 & 129.5 & 0.304 \\
\hline SDNN IDX & 51.9 & 15.0 & 42.7 & 49.5 & 60.8 & 49.5 & 15.2 & 38.5 & 47.8 & 58.4 & 0.127 \\
\hline RMSSD & 32.8 & 14.5 & 22.9 & 29.2 & 36.4 & 36.4 & 18.1 & 23.1 & 32.4 & 42.3 & 0.123 \\
\hline pNN50 & 9.9 & 10.3 & 3.2 & 7.1 & 11.9 & 11.2 & 9.4 & 3.4 & 9.2 & 17.0 & 0.163 \\
\hline TOTPWR & 18472 & 12108 & 10873 & 15952 & 21928 & 17029 & 10776 & 8958 & 14057 & 22697 & 0.288 \\
\hline ULF & 15018 & 10082 & 8177 & 12029 & 18491 & 13872 & 9043 & 7093 & 11412 & 18656 & 0.347 \\
\hline$\underline{V L F}$ & 1892 & 1255 & 1074 & 1668 & 2393 & 1697 & 1206 & 923 & 1336 & 2086 & 0.105 \\
\hline $\mathrm{LF}$ & 896 & 782 & 429 & 704 & 1092 & 744 & 619 & 369 & 556 & 912 & 0.072 \\
\hline $\mathrm{HF}$ & 666 & 694 & 210 & 483 & 757 & 716 & 622 & 261 & 502 & 965 & 0.316 \\
\hline $\mathrm{LF} / \mathrm{HF}$ & 1.74 & 0.99 & 1.03 & 1.60 & 2.08 & 1.28 & 0.74 & 0.81 & 1.03 & 1.51 & $<0.001$ \\
\hline
\end{tabular}

St. Dev. standard deviation.

The $p$-values refer to Wilcoxon test.

with those by Garcia-Garcia re-enforces the importance of computing several HRV parameters, especially the frequency-domain measures, such as LF/HF, which is considered as a non-invasive marker of the sympatho-vagal balance. However, the plausible mechanisms by which abnormal autonomic balance may lead to TOD and, particularly, renal organ damage one are not clearly known. Our results were consistent with two recent studies [20,21], investigating HRV and kidney disease, which concluded that lower HRV (particularly, frequency domain measures) was associated with higher risk of progression to end-stage renal disease and suggested that autonomic imbalance may lead to kidney damage. For that reason, prospective longitudinal studies are needed to evaluate a causal effect between HRV and TOD. In future studies, additional HRV measures, derived from nonlinear [43] and/or point process time-frequency [44] analysis, could be selected either in short-term recordings under standardised conditions [45] or in long-term continuous monitoring [46]. Moreover, other non-invasive parameters related to ANS activity, such as pupillometric features $[47,48]$, could be adopted to provide additional information on autonomic cardiac control. As regards the other factors which entered the adjusted models, the age is the most significant variable, confirming that cardiac, vascular, and renal abnormalities increase progressively with age $[49,50]$. The absence of hypertensive familiarity seems to be associated with no renal involvement. Significantly higher systolic BP values were found in the mild decreased eGFR group, maybe because the blood pressure values are controlled in patients with moderate renal eGFR by the (significantly higher) use of diuretics. Higher systolic BP values were associated with
$\mathrm{LVH}$, coherently with the fact that it is an established cardiac manifestation of chronic hypertension [51]. Moreover, other factors associated with LVH are higher assumption rate of diuretics and higher values of cholesterol. Although previous studies have shown that gender influences HRV parameters both in healthy subjects [52] and hypertensive patients [53], this factor entered no final adjusted models. This means that within the selected sample of patients the gender-related differences in HRV were smaller than differences related to other factors and covariates, in particular age or progression of TOD. We consider in any case that the main limitations of this study were the inherent ones of observational and crosssectional design, which precludes longitudinal analysis between HRV and TOD.

\section{Conclusions}

In conclusion, depressed HRV appeared to be associated with vascular and renal TOD. In particular, depressed values of indexes of the overall ANS modulation on heart were found in patients with plaque compared to those with a normal IMT. These associations remained significant after adjustment for other factors known to contribute to the development of TOD. Moreover LF/HF, a marker of sympatho-vagal balance, was significantly decreased in the groups with mild and moderate decreased eGFR, confirming the involvement of autonomic imbalance in TOD. However, as the mechanisms by which abnormal autonomic balance may lead to TOD are not clearly known, we suggested that further prospective studies with longitudinal design would be performed to investigate HRV in the early stages of hypertension and of TOD development. 
Table 8 Multinomial or binary logistic regression models

\begin{tabular}{|c|c|c|c|c|c|c|c|}
\hline \multirow{2}{*}{$\begin{array}{l}\text { Compared groups } \\
\text { Normal eGFR versus Moderate decreased eGFR }\end{array}$} & \multirow{2}{*}{$\begin{array}{c}\text { HRV measure, factor or covariate } \\
\text { Intercept }\end{array}$} & \multirow{2}{*}{$\frac{\beta}{5.971}$} & \multirow{2}{*}{$\frac{\mathbf{p}}{0.021}$} & \multirow[t]{2}{*}{ OR } & \multicolumn{3}{|c|}{$95 \% \mathrm{Cl}$ of $\mathrm{OR}$} \\
\hline & & & & & & & \\
\hline & LF/HF & 1.000 & 0.038 & 2.718 & 1.057 & to & 6.984 \\
\hline & Systolic BP & -0.003 & 0.779 & 0.997 & 0.974 & to & 1.020 \\
\hline & Age & -0.109 & $<0.001$ & 0.897 & 0.847 & to & 0.948 \\
\hline & Absence of family history of hypertension & 1.082 & 0.047 & 2.951 & 1.014 & to & 8.588 \\
\hline \multirow[t]{5}{*}{ Mild decreased eGFR versus Moderate decreased eGFR } & Intercept & 0.527 & 0.819 & & & & \\
\hline & $\mathrm{LF} / \mathrm{HF}$ & 0.969 & 0.034 & 2.637 & 1.075 & to & 6.465 \\
\hline & Systolic BP & 0.024 & 0.027 & 1.024 & 1.003 & to & 1.046 \\
\hline & Age & -0.058 & 0.020 & 0.943 & 0.898 & to & 0.991 \\
\hline & Absence of family history of hypertension & 0.710 & 0.122 & 2.034 & 0.827 & to & 5.001 \\
\hline \multirow[t]{4}{*}{ Normal IMT group versus Plaque group ${ }^{1}$} & Intercept & 5.552 & 0.002 & & & & \\
\hline & SDNN & 0.018 & 0.024 & 1.018 & 1.002 & to & 1.033 \\
\hline & Age & -0.169 & $<0.001$ & 0.844 & 0.796 & to & 0.896 \\
\hline & Absence of family history of hypertension & 0.347 & 0.532 & 1.415 & 0.476 & to & 4.211 \\
\hline \multirow[t]{4}{*}{ Thickening group versus Plaque group ${ }^{1}$} & Intercept & 2.688 & 0.101 & & & & \\
\hline & SDNN & 0.005 & 0.446 & 1.005 & 0.992 & to & 1.019 \\
\hline & Age & -0.080 & 0.001 & 0.923 & 0.879 & to & 0.970 \\
\hline & Absence of family history of hypertension & -1.072 & 0.071 & 0.342 & 0.107 & to & 1.096 \\
\hline \multirow[t]{4}{*}{ Normal IMT group versus Plaque group ${ }^{1}$} & Intercept & 5.777 & 0.001 & & & & \\
\hline & SDANN & 0.017 & 0.021 & 1.017 & 1.003 & to & 1.032 \\
\hline & Age & -0.169 & $<0.001$ & 0.845 & 0.797 & to & 0.696 \\
\hline & Absence of family history of hypertension & 0.357 & 0.523 & 1.429 & 0.478 & to & 4.270 \\
\hline \multirow[t]{4}{*}{ Thickening group versus Plaque group ${ }^{1}$} & Intercept & 2.626 & 0.101 & & & & \\
\hline & SDANN & 0.006 & 0.351 & 1.006 & 0.993 & to & 1.020 \\
\hline & Age & -0.080 & 0.001 & 0.923 & 0.879 & to & 0.970 \\
\hline & Absence of family history of hypertension & -1.059 & 0.075 & 0.347 & 0.108 & to & 1.112 \\
\hline \multirow[t]{5}{*}{ group with Hypertrophy versus group without Hypertrophy ${ }^{2}$} & Intercept & -5.240 & 0.004 & 0.005 & & & \\
\hline & $\mathrm{LF} / \mathrm{HF}$ & -0.155 & 0.528 & 0.856 & 0.563 & to & 1.302 \\
\hline & Age & 0.068 & $<0.001$ & 1.071 & 1.036 & to & 1.107 \\
\hline & Cholesterol & -0.006 & 0.141 & 0.994 & 0.986 & to & 1.002 \\
\hline & Diuretics & -0.854 & 0.011 & 0.426 & 0.220 & To & 0.823 \\
\hline
\end{tabular}

$\beta$ : regression coefficient.

$\mathrm{p}$ : $\mathrm{p}$-value referred to each variable in the regressions (multinomial or binary logistic).

OR: odds ratio, which is $\exp (\beta)$.

95\% Cl: 95\% confidence interval.

${ }^{1}$ multinomial logistic regression.

${ }^{2}$ binary logistic regression.

\section{Abbreviations}

AVNN: Average of all NN intervals; BP: Blood Pressure; Cl: Confidence Interval; CV: Cardiovascular; ECG: Electrocardiogram; eGFR: estimated Glomerular Filtration Rate; HF: Spectral power of all NN intervals between 0.15 and 0.4 Hz; HR: Heart Rate; HRV: Heart Rate Variability; IMT: Maximum arterial Intima Media Thickness; LF: Spectral power of all NN intervals between 0.04 and $0.15 \mathrm{~Hz}$; LF/HF: Ratio of low to high frequency power; LV: Left Ventricle; LVH: Left Ventricular Hypertrophy; LVMi: LV Mass index; MDRD: Modification of Diet in Renal Disease; OR: Odds Ratio; pNN50: Percentage of differences between adjacent NN intervals that are longer than 50 ms; PSD: Power Spectral Density; RMSSD: Square root of the mean of the sum of the squares of differences between adjacent NN intervals; SDANN: Standard deviation of the averages of NN intervals in all 5-min segments of a 24-h recording; SDNN: Standard deviation of all NN intervals; SDNN IDX: Mean of the standard deviations of NN intervals in all 5-min segments of a 24-h recording; TOD: Target Organ Damage; TOTPWR: Total spectral power of all
NN intervals up to $0.4 \mathrm{~Hz}$; ULF: Spectral power of all NN intervals between 0 and $0.003 \mathrm{~Hz}$; VLF: Spectral power of all NN intervals between 0.003 and $0.04 \mathrm{~Hz}$

\section{Competing interests}

The authors declare that they have no competing interests.

\section{Authors' contributions}

PM participated in study conception and design, analysed data, contributed to interpretation of data and drafted the manuscript. RI collected the data, contributed to interpretation of data and revised critically the manuscript. NDL conceived the study, participated in its design and interpretation of data and helped to draft the manuscript. LP participated in study conception and design, data analysis and interpretation, helped to draft the manuscript. All authors read and approved the final manuscript. 


\section{Authors' information}

PM and LP are biomedical engineers with research interest in biomedical signal processing for cardiologic risk assessment, particularly, by Heart Rate Variability analysis and using artificial intelligence methods. PM acquired ECTS-credits in the field of medicine, particularly cardiology. Moreover, PM and LP got their Ph.D. at the Faculty of Medicine of the University of Naples Federico II (in partnership with the Department of Biomedical, Electronic and Telecommunication Engineering of the same University). RI is a researcher in cardiologic science. NDL is an associate professor in cardiologic science.

\section{Acknowledgements}

The study was conceived and designed in the framework of the research project Remote Health Monitoring (R.H.M.), involving all the authors, and funded by the Regione Campania and of the Ph.D. Scholarship by PM. Moreover, the current work was supported by Italian Ministry of Education, University and Research with the project Smart Health and Artificial intelligence for Risk Estimation (SHARE). LP acknowledges support of this work through the MATCH Programme (EPSRC Grant EP/F063822/1) although the views expressed are entirely his own. The funding bodies have no role in design, in the collection, analysis, interpretation of data, in the writing of the manuscript, or in the decision to submit the manuscript for publication. PM and LP thanks Prof. Marcello Bracale for his scientific leadership (technological issues) in the research project R.H.M.

\section{Author details}

Multidisciplinary Department of Medical Sciences, Second University of Naples, Via Pansini, 5, Naples, Italy. ${ }^{2}$ Departments of Clinical Medicine, Cardiovascular and Immunological Sciences, Federico II University Hospital, Via Pansini, 5, Naples, Italy. ${ }^{3}$ Electrical Systems and optics research division, Faculty of Engineering, University of Nottingham, University Park, Nottingham NG7 2RD, UK.

\section{Received: 23 August 2012 Accepted: 8 November 2012}

Published: 15 November 2012

\section{References}

1. Yusuf S, Reddy S, Ounpuu S, Anand S: Global burden of cardiovascular diseases: part I: general considerations, the epidemiologic transition, risk factors, and impact of urbanization. Circulation 2001, 104(22):2746-2753.

2. Chambless LE, Folsom AR, Clegg LX, Sharrett AR, Shahar E, Nieto FJ, Rosamond WD, Evans G: Carotid wall thickness is predictive of incident clinical stroke: the atherosclerosis risk in communities (ARIC) study. Am J Epidemiol 2000, 151(5):478-487.

3. Hollander M, Bots ML, Del Sol Al, Koudstaal PJ, Witteman JC, Grobbee DE, Hofman A, Breteler MM: Carotid plaques increase the risk of stroke and subtypes of cerebral infarction in asymptomatic elderly: the Rotterdam study. Circulation 2002, 105(24):2872-2877.

4. O'Leary DH, Polak JF, Kronmal RA, Manolio TA, Burke GL, Wolfson SK Carotid-artery intima and media thickness as a risk factor for myocardial infarction and stroke in older adults. N Engl J Med 1999, 340(1):14-22.

5. Lorenz MW, von Kegler S, Steinmetz H, Markus HS, Sitzer M: Carotid intimamedia thickening indicates a higher vascular risk across a wide age range: prospective data from the Carotid Atherosclerosis Progression Study (CAPS). Stroke 2006, 37(1):87-92.

6. Devereux RB, Alderman MH: Role of preclinical cardiovascular disease in the evolution from risk factor exposure to development of morbid events. Circulation 1993, 88(4 Pt 1):1444-1455.

7. Thayer JF, Yamamoto SS, Brosschot JF: The relationship of autonomic imbalance, heart rate variability and cardiovascular disease risk factors. Int J Cardiol 2010, 141(2):122-131.

8. Malik M, Bigger JT, Camm AJ, Kleiger RE, Malliani A, Moss AJ, Schwartz PJ: Heart rate variability: Standards of measurement, physiological interpretation, and clinical use. Eur Heart J 1996, 17(3):354-381.

9. Rajendra Acharya U, Paul Joseph K, Kannathal N, Lim CM, Suri JS: Heart rate variability: a review. Med Biol Eng Comput 2006, 44(12):1031-1051.

10. Parati G, Mancia G, Di Rienzo M, Castiglioni P: Point: cardiovascular variability is/is not an index of autonomic control of circulation. J Appl Physiol 2006, 101(2):676-678. discussion 681-672.

11. Arbolishvili GN, Mareev VY, Orlova YA, Belenkov YN: Heart rate variability in chronic heart failure and its role in prognosis of the disease. Kardiologiya 2006, 46(12):4-11.
12. Musialik-Lydka A, Sredniawa B, Pasyk S: Heart rate variability in heart failure. Kardiol Pol 2003, 58(1):10-16.

13. Melillo P, Fusco R, Sansone M, Bracale M, Pecchia L: Discrimination power of long-term heart rate variability measures for chronic heart failure detection. Med Bio Eng Comput 2011, 49(1):67-74.

14. Pecchia L, Melillo P, Sansone M, Bracale M: Discrimination power of shortterm heart rate variability measures for $\mathrm{CHF}$ assessment. IEEE Trans Inf Technol Biomed 2011, 15(1):40-46.

15. Ueno LM, Drager LF, Rodrigues AC, Rondon MU, Mathias W Jr, Krieger EM, Junior RF, Negrao CE, Lorenzi-Filho G: Day-night pattern of autonomic nervous system modulation in patients with heart failure with and without sleep apnea. Int J Cardiol 2011, 148(1):53-58.

16. Alter P, Rupp H, Rominger MB, Czerny F, Vollrath A, Klose KJ, Maisch B: A new method to assess ventricular wall stress in patients with heart failure and its relation to heart rate variability. Int J Cardiol 2010 139(3):301-303.

17. Vinik Al, Ziegler D: Diabetic cardiovascular autonomic neuropathy. Circulation 2007, 115(3):387-397.

18. Shehab A, Abdulle A: Cognitive and autonomic dysfunction measures in normal controls, white coat and borderline hypertension. BMC CardiovasC Disord 2011, 11(1):3.

19. Oikawa K, Ishihara R, Maeda T, Yamaguchi K, Koike A, Kawaguchi H, Tabata $Y$, Murotani $\mathrm{N}$, Itoh $\mathrm{H}$ : Prognostic value of heart rate variability in patients with renal failure on hemodialysis. Int J Cardiol 2009, 131(3):370-377.

20. Chandra P, Sands RL, Gillespie BW, Levin NW, Kotanko P, Kiser M, Finkelstein F, Hinderliter A, Pop-Busui R, Rajagopalan S, et al: Predictors of heart rate variability and its prognostic significance in chronic kidney disease. Nephrol Dial Transplant 2012, 27(2):700-709.

21. Brotman DJ, Bash LD, Qayyum R, Crews D, Whitsel EA, Astor BC, Coresh J: Heart rate variability predicts ESRD and CKD-related hospitalization. J Am Soc Nephrol 2010, 21(9):1560-1570.

22. Martini G, Rabbia F, Gastaldi L, Riva P, Sibona MP, Morra Di Cella S, Chiandussi L, Veglio F: Heart rate variability and left ventricular diastolic function in patients with borderline hypertension with and without left ventricular hypertrophy. Clin Exp Hypertens 2001, 23(1-2):77-87.

23. Garcia-Garcia A, Gomez-Marcos MA, Recio-Rodriguez Jl, Patino-Alonso MC, Rodriguez-Sanchez E, Agudo-Conde C, Garcia-Ortiz L: Office and 24-hour heart rate and target organ damage in hypertensive patients. BMC Cardiovasc Disord 2012, 12(1):19.

24. De Luca N, Izzo R, laccarino G, Malini PL, Morisco C, Rozza F, lovino GL, Rao MA, Bodenizza $C$, Lanni $F$, et al: The use of a telematic connection for the follow-up of hypertensive patients improves the cardiovascular prognosis. J Hypertens 2005, 23(7):1417-1423.

25. Izzo R, de Simone G, Chinali M, laccarino G, Trimarco V, Rozza F, Giudice R, Trimarco B, De Luca N: Insufficient control of blood pressure and incident diabetes. Diabetes Care 2009, 32(5):845-850.

26. Mancia G, De Backer G, Dominiczak A, Cifkova R, Fagard R, Germano G, Grassi G, Heagerty AM, Kjeldsen SE, Laurent S, et al: 2007 ESH-ESC practice guidelines for the management of arterial hypertension: ESH-ESC task force on the management of arterial hypertension. J Hypertens 2007, 25(9):1751-1762.

27. Expert Panel on Detection, Evaluation, and Treatment of High Blood Cholesterol in Adults: Executive summary of the third report of the national cholesterol education program (NCEP) expert panel on detection, evaluation, and treatment of high blood cholesterol in adults (adult treatment panel III). JAMA 2001, 285(19):2486-2497.

28. Tseng $\mathrm{KH}$ : Standards of medical care in diabetes-2006: response to the american diabetes association. Diabetes Care 2006, 29(11):2563-2564. author reply 2564-2565.

29. Sahn D, DeMaria A, Kisslo J, Weyman A: Recommendations regarding quantitation in M-mode echocardiography: results of a survey of echocardiographic measurements. Circulation 1978, 58(6):1072-1083.

30. laccarino G, Izzo R, Trimarco V, Cipolletta E, Lanni F, Sorriento D, lovino GL, Rozza F, De Luca N, Priante O, et al: Beta2-adrenergic receptor polymorphisms and treatment-induced regression of left ventricular hypertrophy in hypertension. Clin Pharmacol Ther 2006, 80(6):633-645.

31. de Simone G, Izzo R, Chinali M, De Marco M, Casalnuovo G, Rozza F, Girfoglio D, lovino GL, Trimarco B, De Luca N: Does information on systolic and diastolic function improve prediction of a cardiovascular event by left ventricular hypertrophy in arterial hypertension? Hypertension 2010, 56(1):99-104. 
32. Devereux RB, Alonso DR, Lutas EM, Gottlieb GJ, Campo E, Sachs I, Reichek N: Echocardiographic assessment of left ventricular hypertrophy: comparison to necropsy findings. Am J Cardiol 1986, 57(6):450-458

33. Lang RM, Bierig M, Devereux RB, Flachskampf FA, Foster E, Pellikka PA Picard MH, Roman MJ, Seward J, Shanewise JS, et al: Recommendations for chamber quantification: a report from the american society of Echocardiography's guidelines and standards committee and the chamber quantification writing group, developed in conjunction with the european association of echocardiography, a branch of the european society of cardiology. J Am Soc Echocardiog 2005, 18(12):1440-1463.

34. de Luca N, Asmar RG, London GM, O'Rourke MF, Safar ME: Selective reduction of cardiac mass and central blood pressure on low-dose combination perindopril/indapamide in hypertensive subjects. J Hypertens 2004, 22(8):1623-1630.

35. Lembo G, De Luca N, Battagli C, lovino G, Aretini A, Musicco M, Frati G, Pompeo F, Vecchione C, Trimarco B: A common variant of endothelial nitric oxide synthase (Glu298Asp) is an independent risk factor for carotid atherosclerosis. Stroke 2001, 32(3):735-740.

36. 2003 European Society of Hypertension: European society of cardiology guidelines for the management of arterial hypertension. $J$ Hypertens 2003, 21(6):1011-1053.

37. Levey AS, Eckardt K-U, TSukamoto Y, Levin A, Coresh J, Rossert J, Zeeuw D, Hostetter TH, Lameire N, Eknoyan G: Definition and classification of chronic kidney disease: a position statement from kidney disease: improving global outcomes. KDIGO 2005, 67(6):2089-2100.

38. Hamilton P: Open source ECG analysis. In Computers in Cardiology. 2002:101-104

39. Goldberger AL, Amaral LAN, Glass L, Hausdorff JM, Ivanov PC, Mark RG, Mietus JE, Moody GB, Peng C-K, Stanley HE: PhysioBank, PhysioToolkit, and PhysioNet: components of a New research resource for complex physiologic signals. Circulation 2000, 101(23):e215-e220.

40. Lomb: Least-squares frequency analysis of unequally spaced data (in astronomy). Astrophys Space Sci 1976, 39:447-462.

41. Schroeder EB, Liao D, Chambless LE, Prineas RJ, Evans GW, Heiss G: Hypertension, blood pressure, and heart rate variability: the atherosclerosis risk in communities (ARIC) study. Hypertension 2003, 42(6):1106-1111.

42. Berntsen RF, Bonaa KH, Huikuri HV, Rasmussen K: Determinants of cardiac vagal regulation: a cross-sectional study in a general population. Auton Neurosci 2011, 162(1-2):54-59.

43. Melillo P, Bracale M, Pecchia L: Nonlinear Heart Rate Variability features for real-life stress detection. Case study: students under stress due to university examination. Biomed Eng Online 2011, 10(1):96.

44. Kodituwakku S, Lazar S, Indic P, Chen Z, Brown E, Barbieri R: Point process time-frequency analysis of dynamic respiratory patterns during meditation practice. Med Bio Eng Comput 2012, 50(3):261-275.

45. Kluttig A, Schumann B, Swenne C, Kors J, Kuss O, Schmidt H, Werdan K, Haerting J, Greiser K: Association of health behaviour with heart rate variability: a population-based study. BMC Cardiovasc Disord 2010, 10(1):58

46. Pecchia $L$, Melillo P, Bracale M: Remote health monitoring of heart failure with data mining via CART method on HRV features. IEEE Trans Bio Med Eng 2011, 58(3):800-804.

47. Melillo P, Pecchia L, Testa F, Rossi S, Bennett J, Simonelli F: Pupillometric analysis for assessment of gene therapy in Leber Congenital Amaurosis patients. Biomed Eng Online 2012, 11(1):40.

48. Ferrari G, Marques J, Gandhi R, Heller S, Schneider F, Tesfaye S, Gamba H: Using dynamic pupillometry as a simple screening tool to detect autonomic neuropathy in patients with diabetes: a pilot study. Biomed Eng Online 2010, 9(1):26.

49. Kitzman DW, Edwards WD: Age-related changes in the anatomy of the normal human heart. J Gerontol 1990, 45(2):M33-M39.

50. Zabalgoitia M, Rahman SN, Haley WE, Mercado R, Yunis C, Lucas C, Yarows S, Krause L, Amarena J: Comparison in systemic hypertension of left ventricular mass and geometry with systolic and diastolic function in patients $<65$ to $>$ or $=65$ years of age. Am J Cardiol 1998, 82(5):604-608.

51. Dahlof B: Left ventricular hypertrophy and angiotensin II antagonists. Am J Hypertens 2001, 14(2):174-182.
52. Jensen-Urstad K, Storck N, Bouvier F, Ericson M, Lindbland LE, Jensen-Urstad $M$ : Heart rate variability in healthy subjects is related to age and gender. Acta Physiol Scand 1997, 160(3):235-241.

53. Bajko Z, Szekeres CC, Kovacs KR, Csapo K, Molnar S, Soltesz P, Nyitrai E, Magyar MT, Olah L, Bereczki D, et al: Anxiety, depression and autonomic nervous system dysfunction in hypertension. J Neurol Sci 2012, 317(1-2):112-116.

doi:10.1186/1471-2261-12-105

Cite this article as: Melillo et al.: Heart rate variability and target organ damage in hypertensive patients. BMC Cardiovascular Disorders 2012 12:105.

\section{Submit your next manuscript to BioMed Central and take full advantage of:}

- Convenient online submission

- Thorough peer review

- No space constraints or color figure charges

- Immediate publication on acceptance

- Inclusion in PubMed, CAS, Scopus and Google Scholar

- Research which is freely available for redistribution

Submit your manuscript at www.biomedcentral.com/submit
C) BioMed Central 